\title{
DESENVOLVIMENTO E AVALIAÇÃO DE UMA SERVOVÁLVULA DE BAIXO CUSTO PARA A APLICAÇÃO DE INSUMOS LÍQUIDOS
}

\begin{abstract}
ANDRÉ L. JOHANN ${ }^{1}$, EDISON RUSSO ${ }^{2}$, NELSON L. CAPPELLI ${ }^{3}$, CLAUDIO K. UMEZU ${ }^{4}$
RESUMO: O presente trabalho teve o objetivo de desenvolver uma servoválvula de baixo custo, que respondesse a um sinal eletrônico de controle, para a aplicação de insumos líquidos a taxas variáveis. Depois de realizada pesquisa na literatura das opções de válvulas existentes para a dosagem de líquidos a baixas pressões, partiu-se para o desenvolvimento de uma válvula proporcional com acionamento mecânico por intermédio de um servomotor controlado eletronicamente. Uma vez desenvolvida a servoválvula, o sistema foi submetido a um conjunto de testes, realizados em bancada desenvolvida especificamente para esse fim, onde se procurou avaliar seu comportamento em termos de repetitividade, histerese e linearidade. Como resultados, obtiveram-se três curvas de vazão em função do percentual de abertura, descrevendo três incrementos de abertura e fechamento em duas pressões diferentes de trabalho. A servoválvula apresentou boa repetitividade, razoável histerese e curva tipicamente quadrática, bem como manteve a proposta de baixo custo. Esses resultados apresentaram-se bastante satisfatórios, uma vez que a não-linearidade e a histerese podem ser facilmente corrigidas por meio de software.
\end{abstract}

PALAVRAS-CHAVE: agricultura de precisão, taxa de aplicação, válvula proporcional.

\section{DEVELOPMENT AND EVALUATION OF A LOW COST SERVO-VALVE FOR LIQUID INPUTS APPLICATION}

\begin{abstract}
The present work aimed the development of a low cost servo-valve that answers to an electronic control signal, for variable rates liquid inputs application. A literature research to define which valve type should be used was made. A mechanically activated proportional valve with an electronically controlled servo-engine was designed and evaluated. Since developed the servo-valve, the system was submited to a number of tests. The evaluation of its behavior was obtained in terms of repeatability, hystheresis and linearity. The test was accomplished in a bench, specially developed for this aim. As a result, were obtained three curves of opening percentage as function of flow rate, describing three opening and closing increments in two different work pressures. The servo-valve presented a good repeatability, reasonable hysteresis and a typically quadratic curve. This one maintained the low cost target. These results were very satisfied because the non-linearity and the hysteresis could be easily corrected by software.
\end{abstract}

KEYWORDS: precision agriculture, application rate, proportional valve.

\section{INTRODUÇÃO}

Com o desenvolvimento da agricultura moderna, a demanda por técnicas de manejo que possibilitam a aplicação de insumos a taxas variáveis tem aumentado significativamente. Conforme observado por UMEZU (2003), a reposição dos nutrientes e demais aplicações de insumos no solo representam uma das maiores parcelas do custo de produção, dentro da prática de agricultura convencional, e uma quantidade representativa dos insumos utilizados no meio agrícola apresenta-se

\footnotetext{
${ }^{1}$ Eng ${ }^{o}$ Agrícola, Mestrando em Engenharia Agrícola, Laboratório de Instrumentação e Controle - LIC/FEAGRI, Universidade Estadual de Campinas - UNICAMP, Campinas - SP, Fone (0XX19) 3788.1052, andre.johann@ig.com.br

${ }^{2}$ Eng $^{\mathrm{o}}$ Eletricista, Mestrando em Engenharia Agrícola, LIC/FEAGRI/UNICAMP, Campinas - SP.

${ }^{3}$ Eng $^{\mathrm{O}}$ Agrícola, Prof. Doutor, LIC/FEAGRI/UNICAMP, Campinas - SP.

${ }^{4}$ Eng $^{0}$ Eletricista, Prof. Adjunto Doutor, Universidade São Francisco - USF, Campinas - SP.

Recebido pelo Conselho Editorial em: 31-8-2004
}

Aprovado pelo Conselho Editorial em: 30-3-2006 
na forma líquida. FIXEN (1994) já comentava sobre o largo emprego de fertilizantes fluidos nos EUA e a demanda por sistemas de aplicação a taxas variáveis.

Diversas empresas fabricam dispositivos para a aplicação de insumos líquidos por meio de pulverização. Empresas como TeeJet, Jacto, Montana, K.O., AgChem, dentre outras, possuem linhas de produtos destinadas à pulverização desses insumos. Devido à característica da operação de pulverização, tais equipamentos operam a altas pressões e baixas vazões. Por outro lado, não se encontram equipamentos voltados especificamente para a aplicação de insumos líquidos a baixas pressões e em vazões mais elevadas, como é o caso dos fertilizantes e outros insumos líquidos depositados diretamente no solo.

A dosagem de insumos em solução ou suspensões, como é o caso dos fertilizantes líquidos, pode ser feita por meio de bombas ou válvulas dosadoras. Conforme observado em BOARETO et al. (1991), as bombas de pistões, de diafragma ou peristálticas possibilitam o controle do fluxo, controlando-se diretamente a rotação de seus eixos; no entanto, existem restrições quanto à durabilidade e custos. As bombas de diafragma e principalmente as peristálticas apresentam restrições quanto à vida útil dos elementos flexíveis que, com o tempo, alteram a vazão transportada por essas bombas, o que reduz a sua precisão em operações de dosagem. Outras bombas, como as de engrenagens, não chegaram a ser avaliadas para essas aplicações.

Outra opção para o controle do fluxo de insumos líquidos é o emprego de circuitos hidráulicos com válvulas dosadoras. MACYNTYRE (1997) define as válvulas destinadas a essa aplicação como sendo válvulas de regulagem. Nesse caso, a eficiência no controle do escoamento é obtida graças ao estrangulamento que aquelas provocam, enquadrando-se nessa classificação as válvulas de globo, de diafragma e de borboleta.

MACYNTYRE (1997) e THE BRITISH VALVE MANUFACTURERS' ASSOCIATION (1964) descrevem um modelo de válvula de globo denominado válvula de agulha (niddle valve). Tratase de válvula de globo de sede simples, em que o obturador é guiado apenas na parte superior. O obturador apresenta forma afilada, razão pela qual recebeu a denominação de válvula de agulha, prestando-se esses modelos à regulagem fina do fluxo descarregado, trazendo como vantagem simplicidade mecânica e número reduzido de componentes.

Dessa forma, este trabalho teve o objetivo de conceber, projetar, construir e avaliar uma servoválvula de baixo custo, acionada eletronicamente, capaz de operar em sistemas de aplicação de insumos líquidos a taxas variáveis.

\section{MATERIAL E MÉTODOS}

Baseando-se nos trabalhos iniciais realizados por JOHANN \& CAPPELLI (2003), projetou-se e construiu-se um primeiro protótipo da servoválvula, aproveitando-se a base de uma eletroválvula comercial, marca Asco, modelo 8262C090, confeccionada em latão, na qual foi adaptado um servomotor marca Futaba, modelo FP-5148, acionado por modulação por largura de pulso (PWM). Para tanto, foi necessário o desenvolvimento e a construção de um sistema mecânico de acoplamento da válvula ao servomotor.

Para a realização da avaliação da servoválvula, foi construída uma bancada similar à proposta por BOARETO et al. (1991). A bancada constitui-se de um reservatório de água alimentando uma bomba centrífuga, que proporciona pressão e vazão a uma linha hidráulica, na qual está ligada a servoválvula dosadora. $\mathrm{O}$ fluxo de água liberado por essa deixa o circuito depositando-se em um recipiente aberto de volume conhecido. A vazão excedente, não consumida pela mesma, retorna ao reservatório, passando antes por uma válvula de restrição que mantém constante a pressão a montante da linha, sendo o ajuste dessa válvula de restrição feito manualmente. Na Figura 1, apresenta-se o esquema da bancada experimental construída. 


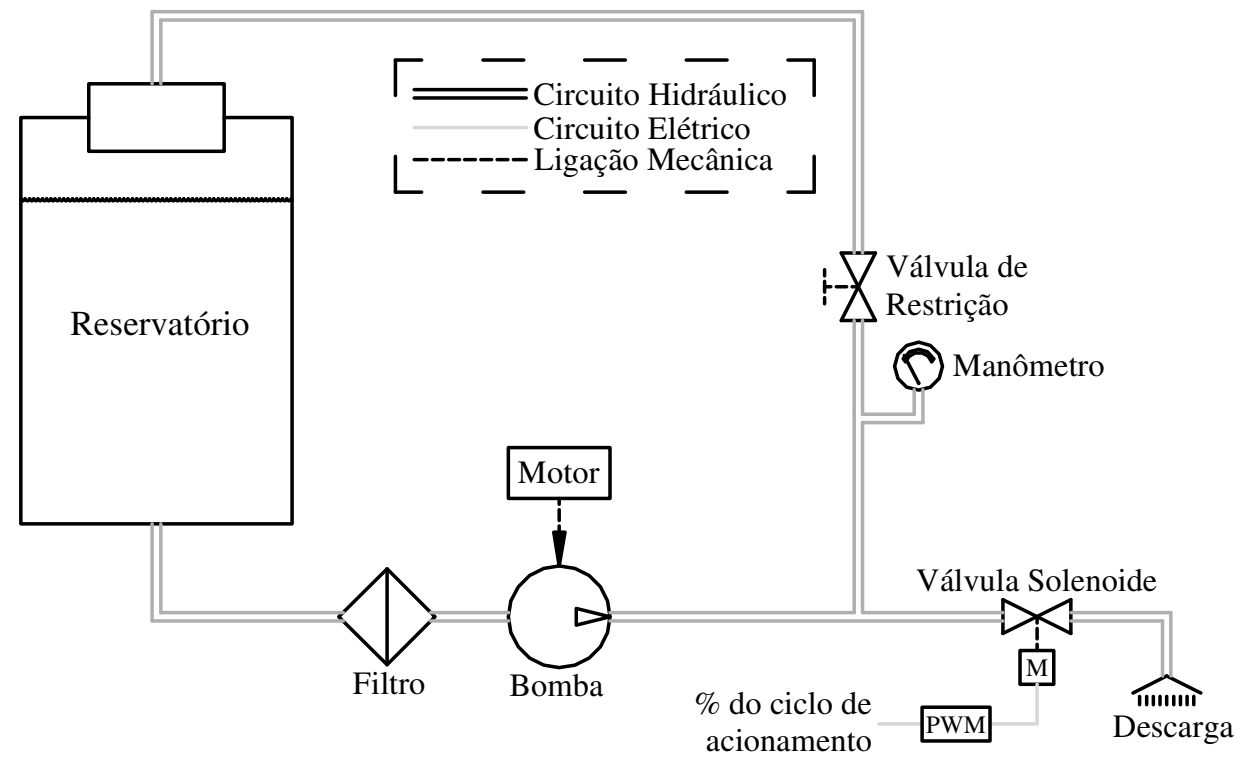

FIGURA 1. Esquema da bancada experimental.

A determinação da vazão foi feita indiretamente por meio da medida do tempo necessário para o enchimento do recipiente de volume conhecido. Depois de realizada a medida, o líquido contido nesse recipiente foi bombeado retornando ao reservatório principal da bancada experimental. Para tornar as leituras mais precisas e facilitar os ensaios, a contagem do tempo foi automatizada, utilizando-se de sensores capacitivos para o disparo e parada de um cronômetro.

Para a avaliação do primeiro protótipo, aplicaram-se os níveis de abertura e fechamento por meio de um gerador de funções arbitrárias marca Agilent, modelo 33220A, gerando um sinal PWM aplicado ao servomotor. O período do sinal foi fixado em $17 \mathrm{~ms}$, e o tempo ativo (duty-cicle) variava de zero a $2 \mathrm{~ms}$, obtendo-se resposta linear de movimento angular de zero a 180 graus.

A avaliação constituiu-se do levantamento das curvas de vazão em função da abertura (FIGURA 3), em três repetições, nas operações de abertura e de fechamento, à pressão de $100 \mathrm{kPa}$. O líquido utilizado nesses experimentos foi água à temperatura ambiente.

A avaliação do primeiro protótipo mostrou haver inflexão na curva de abertura da servoválvula, identificada como sendo devido à folga nas roscas dos fusos. Para a correção dessa característica indesejável, construiu-se um segundo protótipo, inserindo-se uma mola para a eliminação do efeito dessa folga.

A avaliação do segundo protótipo foi realiza em dois grupos de ensaios. No primeiro, foi mantida a pressão nominal a montante da servoválvula em $100 \mathrm{kPa}$. No segundo, a pressão nominal foi mantida em $50 \mathrm{kPa}$. Com esse procedimento, foi possível avaliar a repetitividade, a histerese e a nãolinearidade.

\section{RESULTADOS E DISCUSSÃO}

\section{Protótipos da servoválvula}

Para a montagem da servoválvula, incorporou-se sobre a base da eletroválvula um corpo usinado de aço-carbono que acomoda um fuso e a agulha, sendo essa última feita em aço inoxidável. A vedação entre a agulha e o corpo da válvula é feita por intermédio de um anel de elastômero (O'ring) e por um anel de aço inoxidável. Desse modo, apenas as partes da válvula que entram em contato com o fluido necessitam ser construídas com material que resista à abrasão e à corrosão. 
Foi desenvolvido um primeiro protótipo que foi aprimorado por meio da inclusão de uma mola pressionando a rosca do fuso, obtendo-se um segundo protótipo. Na Figura 2, tem-se uma vista em explosão com a denominação dos componentes, bem como a vista em corte referente ao segundo protótipo, ou seja, a versão final da servoválvula.

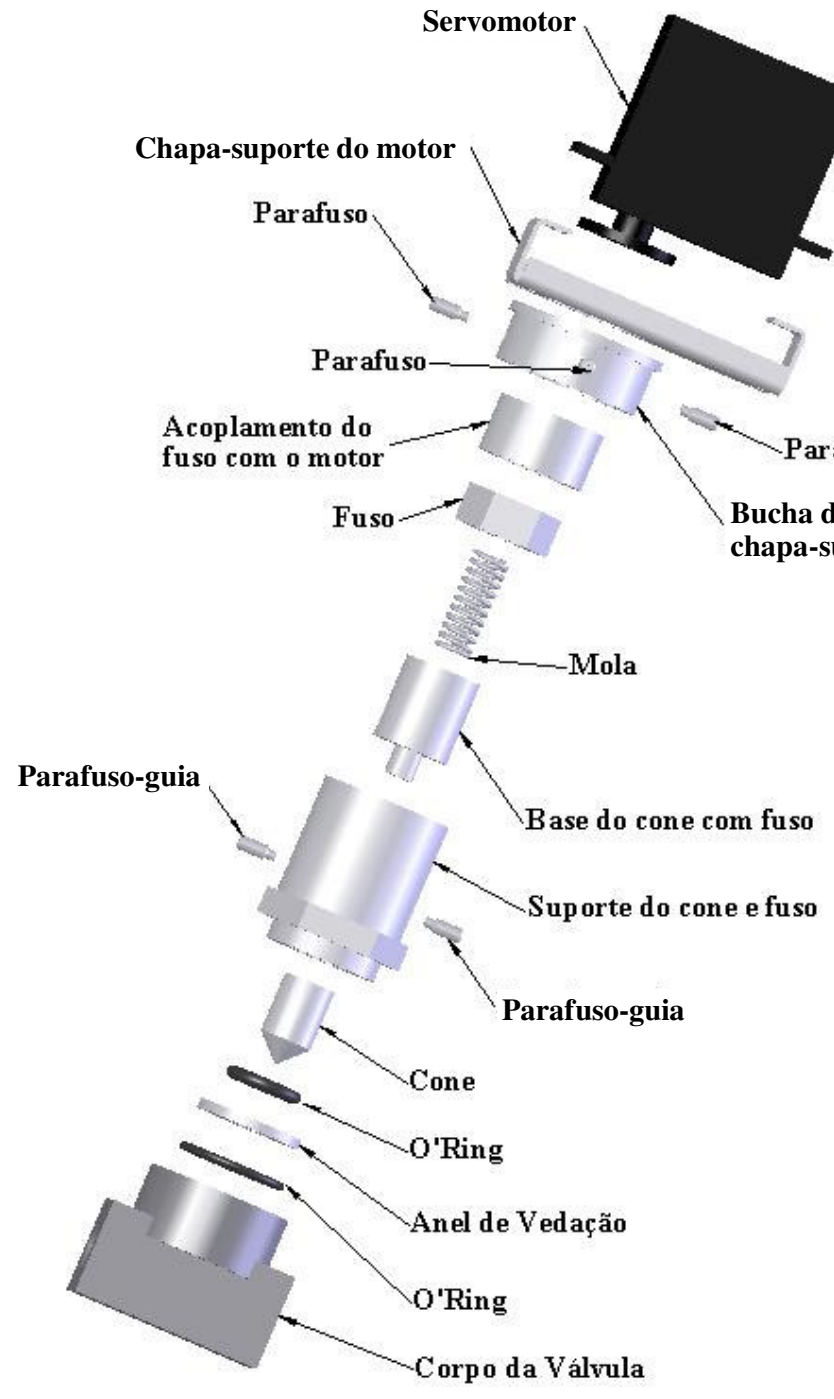

a)

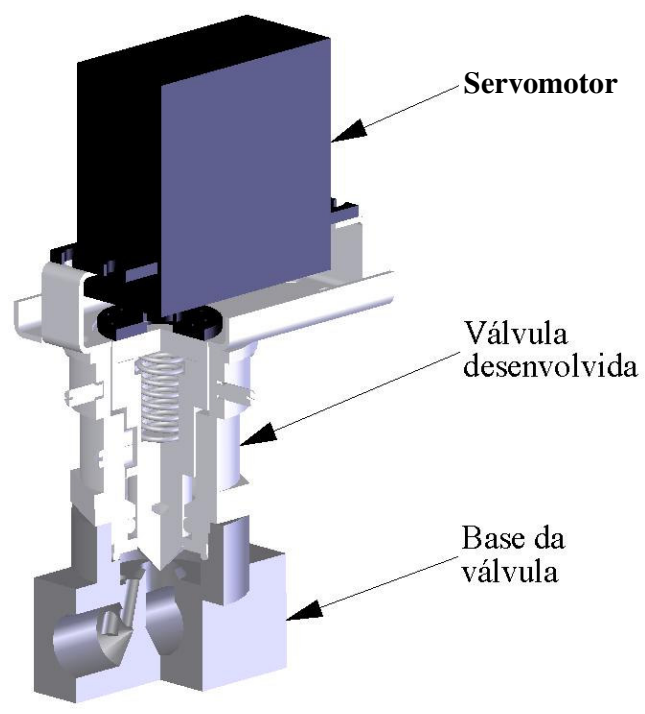

b)

FIGURA 2. Versão final da servoválvula desenvolvida. a) Vista em explosão. b) Vista em corte.

O controle da vazão é feito por meio do deslocamento axial da agulha, denominada de cone, proporcionado pelo fuso quando submetido ao movimento giratório do servomotor. A lubrificação das roscas do fuso foi feita por meio de graxa de petróleo.

Para reduzir os problemas de entupimento, tanto o orifício no corpo da válvula quanto a extremidade da agulha apresentam formato cônico, o que forma apenas uma linha de contato entre os dois componentes quando a servoválvula está completamente fechada. No entanto, essa alternativa apresentou problemas no fechamento total da mesma, a qual ainda apresenta pequeno fluxo remanescente.

\section{Avaliação do primeiro protótipo}

Nos ensaios com o primeiro protótipo, obtiveram-se as curvas descritas na Figura 3. 


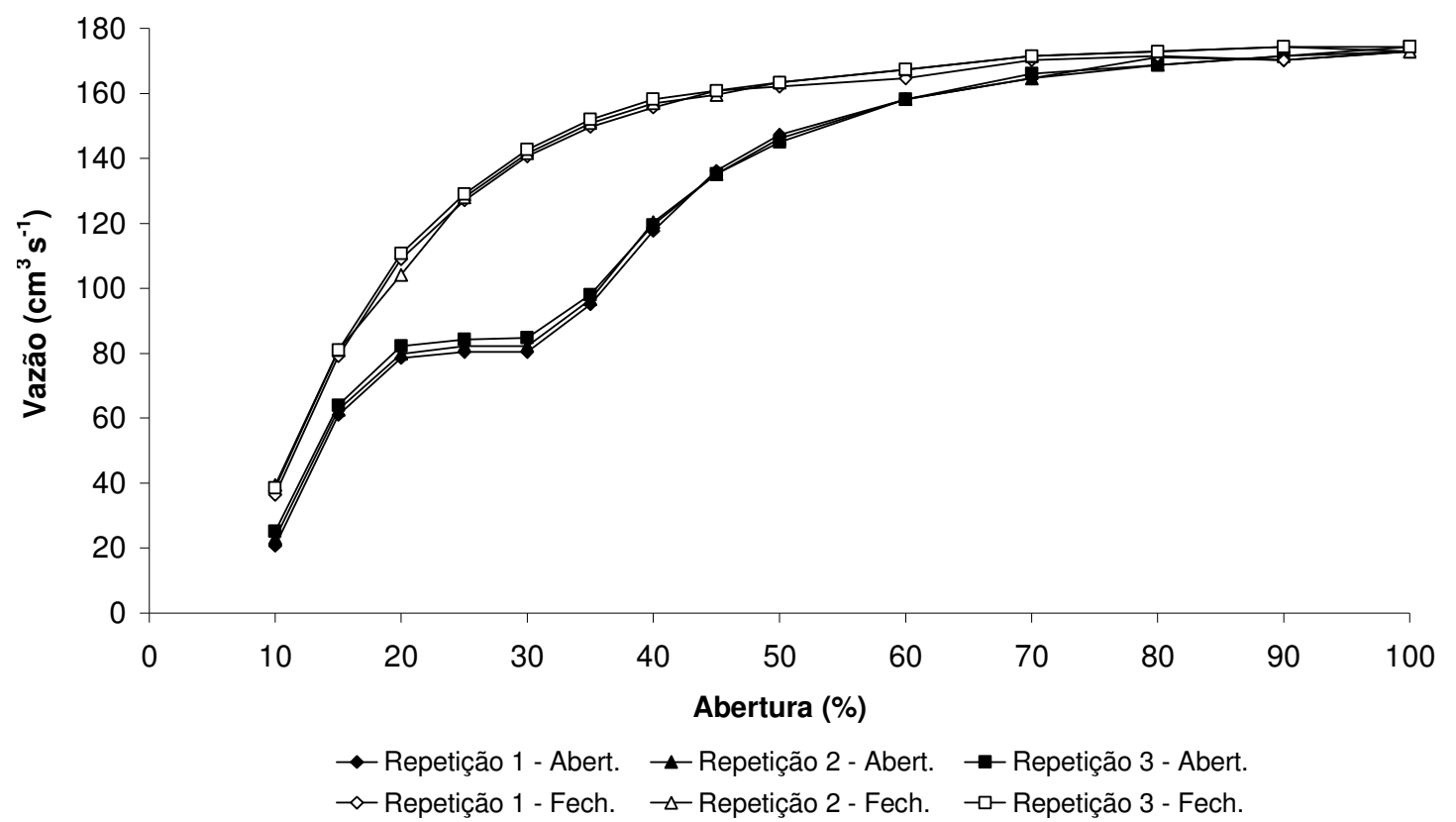

FIGURA 3. Resultados dos ensaios com o primeiro protótipo da servoválvula, na pressão de $100 \mathrm{kPa}$, em operação de abertura e fechamento.

Esse protótipo apresentou problemas de elevada não-linearidade nas operações de abertura, bem como inflexão na curva, o que inviabilizaria o seu emprego nesse tipo de operação. Além disso, puderam-se observar problemas de baixa repetitividade, o que também comprometia a sua precisão.

\section{Avaliação do segundo protótipo}

No primeiro grupo de ensaios com o segundo protótipo, obtiveram-se as curvas descritas na Figura 4, para as operações de abertura e fechamento da servoválvula, à pressão de $100 \mathrm{kPa}$.

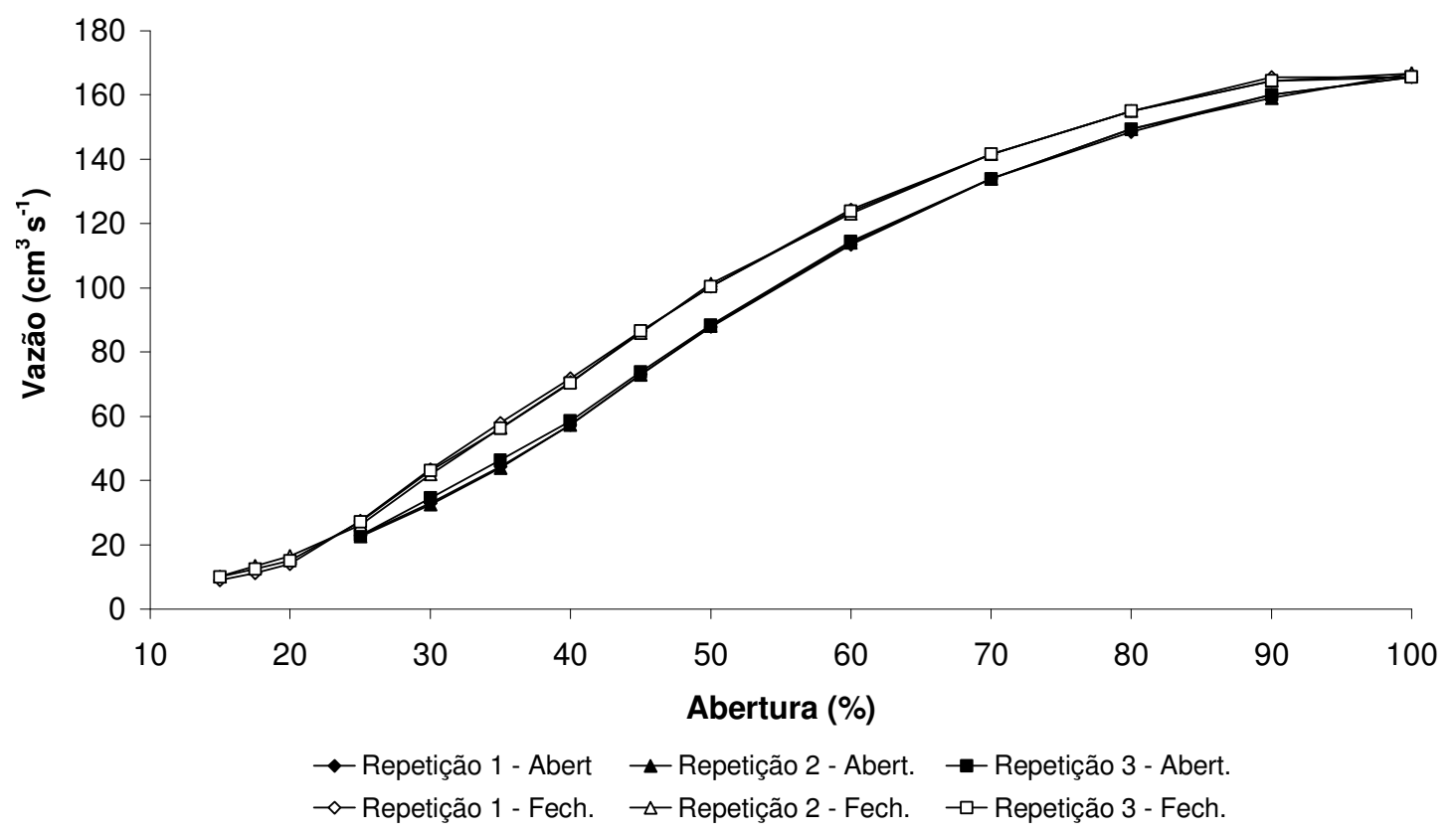

FIGURA 4. Resultados do primeiro grupo de ensaios do segundo protótipo de servoválvula, à pressão de $100 \mathrm{kPa}$, em operação de abertura e fechamento. 
A curva de abertura só descreve valores de abertura a partir de $25 \%$ do ciclo de trabalho, valor pelo qual se passou a observar fluxo efetivo.

No segundo grupo de ensaios, obtiveram-se as curvas descritas na Figura 5, para as operações de abertura e fechamento, à pressão de $50 \mathrm{kPa}$.

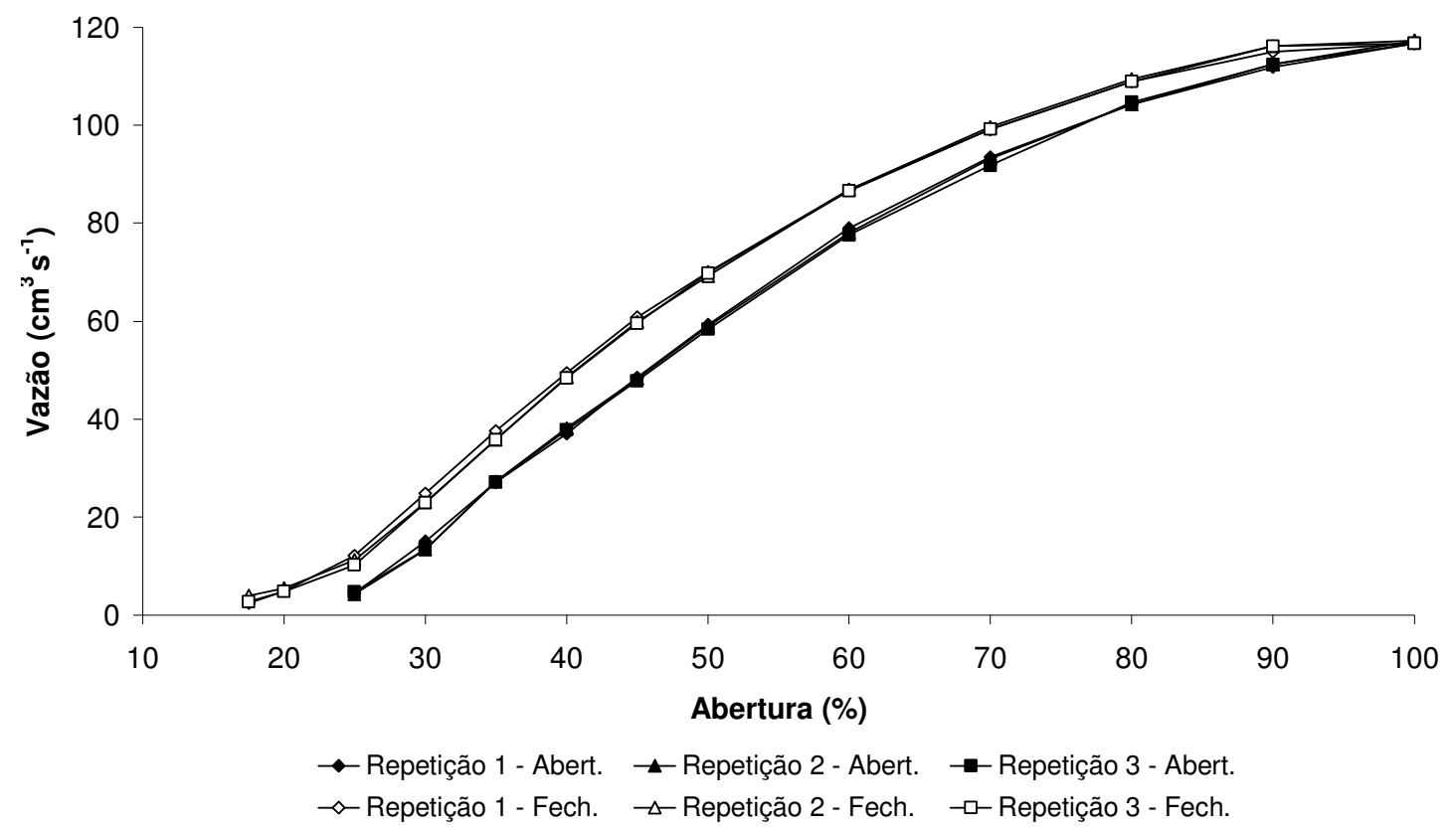

FIGURA 5. Resultados do segundo grupo de ensaios do segundo protótipo de servoválvula, à pressão de $50 \mathrm{kPa}$, em operação de abertura e fechamento.

Conforme pode ser observado, há a presença de inflexão na curva para valores abaixo de $25 \%$ do ciclo de trabalho, nas operações de fechamento, o que faz com que esses não sejam bem descritos por meio de função polinomial quadrática. Além disso, observa-se perda de repetitividade nesse intervalo, o que pode ser um problema, visto que esse erro representa razoável percentual da vazão liberada pela servoválvula a essa abertura. Por esse motivo, optou-se por descartar a sua utilização em aberturas inferiores a $25 \%$ de ciclo de trabalho.

No primeiro grupo de ensaios, a pior situação quanto à repetitividade ocorreu aos $40 \%$ do ciclo de trabalho das operações de fechamento, sendo de $2,7 \mathrm{~cm}^{3} \mathrm{~s}^{-1}$ a maior diferença de vazões entre um ensaio e outro, o que representa $1,6 \%$ da vazão máxima. Entre $50 \%$ e $60 \%$ do ciclo de trabalho, a servoválvula apresentou diferença de vazões médias de $11,0 \mathrm{~cm}^{3} \mathrm{~s}^{-1}$ entre as operações de abertura e fechamento, o que representa $6,4 \%$ da sua vazão máxima. Nas operações de abertura, entre $35 \%$ e $45 \%$ do ciclo de trabalho, nota-se variação na tendência da curva, apresentando pequena inflexão. Nas demais faixas, tanto na abertura quanto no fechamento, notou-se comportamento típico de uma função polinomial do segundo grau, apresentando $R^{2}=0,9997$, na operação abertura, e $R^{2}=0,9998$, na operação de fechamento.

No segundo grupo de ensaios, a pior situação quanto à repetitividade ocorreu aos $25 \%$ do ciclo de trabalho das operações de fechamento, sendo de $1,9 \mathrm{~cm}^{3} \mathrm{~s}^{-1}$ a maior diferença de vazões entre um ensaio e outro, o que representa 1,6\% da vazão máxima. Entre $40 \%$ e $50 \%$ do ciclo de trabalho, a servoválvula apresentou diferença de vazões médias de $11,9 \mathrm{~cm}^{3} \mathrm{~s}^{-1}$ entre as operações de abertura e fechamento, o que representa $10,1 \%$ da sua vazão máxima. Nas operações de abertura, entre $35 \%$ e $45 \%$ do ciclo de trabalho, nota-se variação muito pequena na tendência da curva, resultando em leve inflexão. Em todo o intervalo de trabalho, a servoválvula mostrou comportamento típico de uma 
função polinomial do segundo grau, apresentando $R^{2}=0,9991$, na operação abertura, e $R^{2}=0,9998$, na operação de fechamento.

Utilizando-se dos valores médios das curvas correspondentes às três repetições, dentro de cada ensaio, conforme metodologia proposta por NETO et al. (2002), obtiveram-se as funções polinomiais com os seus respectivos coeficientes de ajuste $\mathrm{R}^{2}$. Na Figura 6, apresentam-se as curvas dos valores médios dos ensaios com as suas respectivas funções polinomiais.

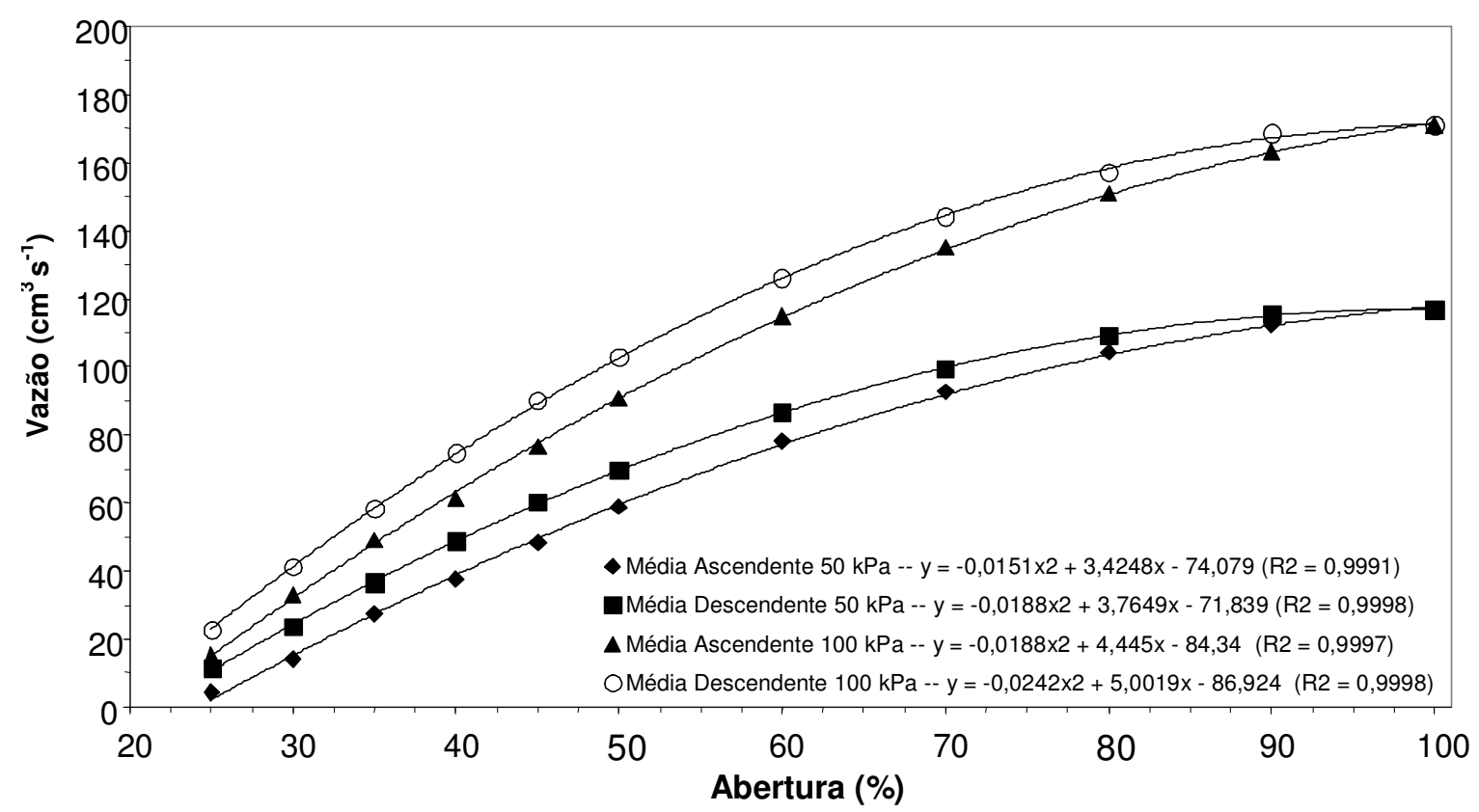

FIGURA 6. Dados médios com as respectivas funções polinomiais e curvas de ajuste quadráticas.

A servoválvula desenvolvida apresentou comportamento satisfatório nos incrementos de abertura e fechamento, com boa repetitividade, comportamento quadrático e a presença de histerese.

O comportamento quadrático não representa problemas para a sua utilização, visto que tal comportamento pode ser compensado por software.

O problema da histerese pode ser resolvido efetuando-se o ajuste da vazão apenas na abertura ou apenas no fechamento. Tal operação pode ser facilmente implementada por software, ou mesmo por microcontrolador incorporado ao circuito de acionamento da servoválvula.

O fluxo remanescente observado, quando a servoválvula se encontra completamente fechada não constitui, necessariamente, um problema, visto que, durante a operação, ela atende à função de dosar insumos líquidos. No caso da necessidade de uma interrupção total do fluxo, pode-se adicionar uma válvula do tipo aberta/fechada instalada a montante da servoválvula.

A servoválvula apresenta limitação no seu uso em aberturas abaixo de $25 \%$ do ciclo de trabalho, o que restringe a sua vazão mínima. No entanto, o seu emprego ainda é viável se adotada em dosagem de componentes com menor concentração.

É possível melhorar a resposta em pequenas vazões, por meio do uso de agulha com cone de perfil parabólico ou outro polinômio de ordem superior, porém essa solução certamente dificultará a sua fabricação, conseqüentemente, elevando o seu custo. 


\section{Custo de fabricação}

O custo de fabricação do protótipo foi levantado na região de Ribeirão Preto - SP, no mês de maio de 2004. Os dados relativos a esse levantamento estão apresentados na Tabela 1.

TABELA 1. Levantamento de custo de construção da servoválvula proposta.

\begin{tabular}{|c|c|c|c|c|}
\hline \multirow[t]{2}{*}{ Descrição } & Mão-de-obra & Matéria-Prima & Material & $\begin{array}{c}\text { Produto } \\
\text { Manufaturado }\end{array}$ \\
\hline & \multicolumn{4}{|c|}{ Custo $(\mathrm{R} \$)$} \\
\hline Servomotor & - & - & - & 56,00 \\
\hline Chapa de suporte do motor & 5,00 & 0,46 & Inox & \\
\hline Bucha de fixação da chapa-suporte & 3,00 & 0,10 & aço 1045 & \\
\hline Acoplamento do fuso com o motor & 2,00 & 0,08 & aço 1045 & \\
\hline Fuso & 3,00 & 0,04 & aço 1045 & \\
\hline Base do cone com o fuso & 5,00 & 0,04 & aço 1045 & \\
\hline Mola & - & - & Aço mola & 0,10 \\
\hline Cone & 2,00 & 0,19 & Inox & \\
\hline Suporte do cone e fuso & 3,00 & 0,31 & aço 1045 & \\
\hline Anel de vedação & - & - & Inox & 0,10 \\
\hline Corpo da válvula & 6,00 & 3,00 & Inox & \\
\hline Parafusos & - & - & Aço oxidado & 0,20 \\
\hline O'rings & - & - & Elastômero & 1,00 \\
\hline Montagem & 5,00 & - & - & - \\
\hline Custos Parciais (R\$) & 34,00 & 4,22 & & 57,40 \\
\hline Custo Total (R\$) & & & & 95,62 \\
\hline
\end{tabular}

O custo de fabricação do protótipo foi de aproximadamente R \$ 96,00 (US\$ 40,00 convertidos ao câmbio de R\$2,40 por dólar americano) por unidade, sendo esse valor passível de redução em produção em larga escala.

Conforme relatado na introdução deste trabalho, não foram encontrados equipamentos voltados especificamente para a aplicação de insumos líquidos a baixas pressões e em vazões elevadas. A válvula comercial que mais se assemelhou à desenvolvida foi a DirectoValve, modelo 344BR-23-01C, fabricada pela TeeJet. Trata-se de uma válvula destinada ao controle da pressão em sistemas de pulverização, utilizando uma esfera de polipropileno acionada por motor elétrico de $12 \mathrm{Vdc}$, com conexões de $19,05 \mathrm{~mm}$ de diâmetro, apresentando vazão máxima de $2.016 \mathrm{~cm}^{3} \mathrm{~s}^{-1}$ à pressão nominal de $2.068 \mathrm{kPa}$. No entanto, dadas as suas características, não se adapta ao sistema de aplicação de fertilizantes líquidos proposto. Essa válvula comercial apresenta preço de tabela aproximado de U\$ 271,00.

Todos os componentes empregados na fabricação do protótipo são de baixo custo e seu processo de fabricação é relativamente simples, preservando, assim, a proposta inicial deste trabalho.

\section{CONCLUSÕES}

A configuração da servoválvula desenvolvida apresentou-se adequada quanto ao comportamento de vazão na faixa proposta e quanto ao baixo custo de fabricação.

\section{REFERENCIAS}

BOARETO, A.E.; CRUZ, A.P.; LUZ, P.H.C. Adubo líquido: produção e uso no Brasil. São Paulo: Fundação Cargill, 1991. 100 p. 
FIXEN, P.E. Fluid fertilizers in an evolving agriculture. In: SIMPÓSIO BRASILEIRO SOBRE FERTILIZANTES FLUÍDOS, 1993, Piracicaba. Anais... Piracicaba: Potafos, 1994. p.1-30.

JOHANN, A.L.; CAPPELLI, N.L. Seleção e modelagem matemática de uma válvula dosadora a ser empregada na aplicação de fertilizantes líquidos a taxas variáveis. In: WOKSHOP DE PÓS-

GRADUAÇÃO: O WORKSHOP DAS ÁREAS DE CONCENTRAÇÃO, 4., 2003, Campinas. Anais... Campinas: Faculdade de Engenharia Agrícola da UNICAMP, 2003. 1 CD-ROM.

MACINTYRE, A.J. Bombas e instalações de bombeamento. 2.ed. Rio de Janeiro: Livros Técnicos e Científicos, 1997. 635 p.

NETO, B.B.; SCARMINIO, I.S.; BRUNS, R.E. Como fazer experimentos: pesquisa e desenvolvimento na indústria. 2.ed. Campinas: Editora da UNICAMP, 2002. 250 p.

THE BRITISH VALVE MANUFACTURERS' ASSOCIATION. Valves for the control of fluids. Manchester: C. Nicholls \& Company, 1964. 344 p.

UMEZU, C.K. Sistema de controle de um equipamento de formulação, dosagem e aplicação de fertilizantes sólidos a taxas variáveis. 2003. $171 \mathrm{f}$. Tese (Doutorado em Máquinas Agrícolas) Faculdade de Engenharia Agrícola, Universidade Estadual de Campinas, Campinas, 2003. 